\title{
Practical Realities and Emotions in Field Research: The EXPERIENCE OF NOVICE FIELDWORKERS
}

\author{
Travis SATTERLund \\ North Carolina State University \\ and \\ Christine Mallinson \\ University of Maryland, Baltimore County
}

Accounts of how seasoned researchers negotiate the relationship between emotions and fieldwork are becoming more prevalent in the qualitative literature but those by novices are rare. We describe the experiences of four sociology graduate students newly enrolled in a qualitative field methods course at a public research university. Using data from post hoc personal reflections, we analyze how fieldwork raises emotions that affect site selection and data analysis. We offer the suggestion to novice researchers and those who teach qualitative courses to anticipate emotional challenges in beginning field projects.

Accounts of fieldworkers' successes and failures in negotiating the relationship between emotions and fieldwork are becoming more prevalent in the qualitative social science literature (Ellis 1991, 1995; Goode 1996; Kleinman 1991; Kleinman and Copp 1993; McGrath, Martin, and Kulka 1982; Van Maanen 1988, 1995). However, the perspective of students struggling with the bureaucratic demands related to graduate coursework on the one hand and the unpredictable demands of the field on the other is less often discussed than are the experiences of seasoned field researchers. One particular challenge for new researchers for whom fieldwork can be a "shock" (Van Maanen, Manning, and Miller 1993:viii) is 
the emotional process of immersion into an unfamiliar setting with a group of skeptical strangers.

In this paper, we describe the experiences of four graduate students enrolled for the first time in a qualitative field methods course at a public research university. Our primary focus is on the practical realities we faced as first-time field researchers, as well as the process by which we as neophytes learned to become mindful of our emotions while conducting field research. ${ }^{1}$ Though inclass discussions, course readings, and constructive criticism by our professor often touched on the emotional connections between the researcher and the field research being conducted, we were unable to fully appreciate their relevance until the last week of class when we read an article about how to teach fieldwork (Kleinman, Copp, and Henderson 1997). As we began to personally evaluate our semester-long stints as fieldworkers, the emerging realization that our perceptions and analyses of our field sites had been shaped by our emotions prompted analytical breakthroughs and helped us sharpen our sociological understandings.

After understanding how emotions had been central to our learning process as field researchers and as sociologists, we decided to write a paper designed specifically for novice graduate student field researchers that could complement a piece like Kleinman, Copp, and Henderson (1997). While their article is written from the perspective of expert fieldworkers teaching novice students, this paper is informed by the perspectives of novice researchers who did not anticipate the emotional impact field research would entail. Moreover, though countless others may have written about their "tales from the field" and the wide array of potential problems faced by ethnographic researchers while in the field (Ellis 1995; Goode 1996; Labaree 2002; Monti 1992; Sieber 1982; Van Maanen 1988; Wax 1979), we believe that our experience as first-time graduate student field researchers offers a fresh and unique perspective to these problems.

Using data gathered from personal reflections in the form of five-to-10-page freewrite-style essays written by each student following the course, we report on when our emotions surfaced in the fieldwork process, cover several of the specific "fieldwork taboos" 
we faced and the emotions they raised, discuss how and with what success we confronted these emotions, and reflect on how our emotions affected our field research itself, primarily our site selection and sociological analyses. We close with suggestions for firsttime field researchers, as well as instructors who teach courses geared toward these students. By detailing our experiences, we hope to help other neophyte researchers anticipate the emotional shocks they might encounter in the field, as well as offer some insight to those who teach qualitative research courses.

\section{Learning to Conduct Field Research}

When I walked into class that Wednesday afternoon, I had no idea what to expect. I thought, how different can this be from all the other classes I had taken in research? Boy was I wrong.

In contrast to the quantitative methods classes that we had encountered during our tenure as advanced sociology graduate students, the course on qualitative field research in which we were newly enrolled took an active learning approach (Astin 1993). As such, students were expected and required to experientially engage in the course material. On the first day of class, our professor grabbed our attention by explaining that it would be necessary to "lose" the methods that we had previously been taught in statistics-oriented courses. Instead, our thinking would have to be different. Rather than looking to a hard and fast theory to guide our research, we were told that our data would drive our research. Of course, as we went along we would learn that this process, as is often the case in quantitative research, is rarely linear, and we would thus go back and forth between data and theory. However, we would only learn this process in practice.

We were told that we needed to find a viable, accessible research site that interested us, one where we could commit ourselves to spending at least an hour a week over the next 15 weeks. Our initial instructions were to write down everything that happened at our sites, aiming for five to ten pages of single-spaced field notes per hour of fieldwork. "Everything is data," our profes- 
sor told us, "every word, every action, every emotion." We were also required to write notes on notes (Lofland and Lofland 1984), which were to constitute a running analytic commentary on our data. While the field notes were our hard data, the notes on notes, our professor explained, were to be our perceptions about and reflections on what we observed in our sites. It was all foreign to us, and though we voiced none of our concerns, these expectations and the plan itself sounded a little vague and perhaps even a bit suspect.

Shouldn't I have a hypothesis to work from? Shouldn't I do some reading first to get an idea of what to look for in the site or what type of site I should go after? The answer to both questions was NO. No? But all research requires that you have a hypothesis and review the literature before beginning the research. That was what all the research classes had taught me and what I taught my students in Introduction to Sociology. Now here was an accomplished professor telling me that what I had learned wasn't the only way to conduct research.

We quickly found that gaining access to field sites is not necessarily an easy task. As we began the process of "getting in," we had several false starts, which forced us to face emotions ranging from insecurity, to fear, to embarrassment. As one of us tried to gain access to a middle school to study students, he worried about not being taken seriously, since getting into the site would require him to demonstrate his credentials and legitimate his study to gatekeepers; indeed, he was denied access to the site. ${ }^{2}$ Two of us were also rejected outright, simply told by those in charge that our projects were not a good idea. One researcher discovered these difficulties in her first attempt at contacting a Girl Scout troop.

I wanted to observe a group of Girl Scouts ... but before I could even ask permission to sit in on their meetings, the leader started asking me all kinds of questions. Would my results be published? Would I actually be stating that I had observed a Girl Scout troop? What did I hope to find out from the research? I felt like I was being grilled. . I was sort of happy when she called me back the next week and said that some of the girls' parents 
didn't like the idea of my project. I was more than ready to try to contact another troop that I hoped would be more open and receptive.

We knew it was important to be clear with our subjects and let them know up front that we were researchers with objectives. However, one researcher learned that impulsively telling a lie to legitimate his presence at a hockey rink was a mistake that cost him the chance to observe at that site. While at the hockey rink, the researcher engaged in a conversation with a parent of a hockey player. When the parent asked him about the reason for his presence at the rink that day, the researcher impulsively said that he was a father of a four-year-old boy and was interested in hockey for his son. In truth, the researcher's son was only two years old, and the reason for being at the rink was not about hockey but rather about field research. The researcher had not intended to deceive any potential research participants; he simply wanted to show he belonged at the site. Still, this spur-of-the-moment miscalculation was an unnecessary lie and coming to grips with it was painful for the researcher.

I knew as soon as I said it that I had goofed. I felt like a teenager lying to my parents - it just felt awful because I knew I would have to face the music. All I could think about was what this meant to my field research. For three days after it [the lie] happened until our class met again I was a wreck. I just didn't know what to do. Of course everything was swirling around in my head: Do I go back and find the guy that I lied to and try to make the situation right? Do I act like it never happened? Should I tell my professor? Every conceivable action was running through my head. I had been at my site for over a month and I already felt invested in it. I didn't want to start over. Worse, I wasn't sure if my classmates and professor needed to be privy to my screw-up ... With my lie I was worried that I would be seen as incompetent and unprofessional by admitting the problems. I was embarrassed to do such a stupid thing. It also exacerbated the nagging feeling that my colleagues in the class were handling their research situations much better than I. 
This researcher's experience highlights the ethical dilemma of owning up to a lie and deciding whether or not to continue to pursue the original research. Although we had covered research ethics in the second week of class, on paper the examples seemed so cut and dry. In contrast, the hockey rink episode was much more of a gray area, more of a "white lie" than any of the examples of ethical misconduct we had read about. But with this blunder as a catalyst for discussion, the class revisited the topic of ethics and the concept of trust in the field. With some prodding from our instructor, and the honesty of the researcher who told about his dilemma, the class began to understand how this "little white lie" was actually a "whopper" in terms of research ethics. ${ }^{3}$ This experience taught everyone how messy the process of legitimating ourselves in the field can become.

The embarrassing and awkward situations we faced while trying to get into our field sites also raised the issue of the emotional closeness that field research requires. In class discussions, our professor urged us to be mindful of our emotions and to document how we felt as we conducted fieldwork. We were assigned to read the appendix of Kleinman and Copp (1993) and consider their questions and recommendations for how fieldworkers can explore and analyze emotional connections between themselves and their research participants. Other readings (e.g. Lofland and Lofland 1984:47) made similar points about the challenging personal issues that field researchers often face, ranging from fear and loathing to feelings of over-attachment, the temptation to convert, and struggles over values and subjectivity. As we started to face some of these issues ourselves, we began to realize, if only superficially, that immersing ourselves in others' lives is taxing. As one student put it,

Once in the field, I found many of the emotionally challenging aspects common to any interpersonal relationship present to a far greater extent than I had expected. I found it impossible to distance myself from my subjects, as is so easy the case in quantitative studies .... Although realizing this necessity for greater closeness prior to entering the field, I still held to the notion that I could remain unattached to those studied, not only because of my exposure to more positivistic and quantitative 
approaches, but also because I tend to be rather withdrawn and distant from others in general.

Three of us ended up at sites that were not our first choices. Eventually, having made it past our false starts, we gained access to four different sites: a police station, a center for troubled teens, a boxing gym, and the regular meeting place of a Girl Scout troop. For our own amusement, we called ourselves "The Qualitative Breakfast Club." We did not realize at the outset the extent to which our fieldwork would draw us away from the comfort of our cubicles and computers, or how much our access to field sites would depend on communicative skill - in contrast to our previous methods classes, which had never mentioned interpersonal ability as important for doing sociological research.

We soon discovered how much time and energy field research requires. While observing at our sites, our main task was to write down everything that was said and done at the site, in as much detail as we could capture. This involved jotting down the overall field site scene, writing short notes (when possible), and later developing our jottings, notes and mental pictures into fully completed field notes. "Everything is data," we were reminded repeatedly by our professor, and we were encouraged by him to attempt to remember every detail of the interactions that took place in our field sites. We were expected to remember not only the details of each scene, but also to transcribe as closely as possible what people said in conversation with each other as well as with us. This task tested our memory skills and was particularly difficult for us as graduate students who often aspire to perfection.

[Writing down everything] proved to be more difficult than I imagined. While I was able to capture events as they took place from the beginning, I was having a great deal of trouble remembering conversations verbatim. As a result my field notes in the first three weeks or so were often summaries of conversations.

Even more frustrating was the fact that this fieldwork process took so much time. We spent an hour each week observing, an 
additional seven or eight hours each week typing up our observations, and more time thinking about what we had observed and recording our own thoughts in our notes on notes. Taking into account the four or five readings we also were assigned, this course easily took up more time than all our other courses that semester combined.

On an academic level, from the perspective of graduate students doing research and taking other courses simultaneously, the workload from this one course in qualitative fieldwork surprised us all. Although we all had heard from previous students who had taken the class that the workload was "heavy," it wasn't until we each had to write up our field notes and notes on notes, week after week after week, that we realized how intensive field research is.

Similarly, as the police station researcher put it,

Each week I would sit at my computer for at least five hours typing full field notes. I never dreamed it would take so much time. It is one thing to hear a person talk about the amount of time it takes to write up field notes or read about the length of time it takes; it is quite another matter to do it yourself. Before it was all said and done, I came to dread this part of the research. Yes, I knew it was vital, for these notes were my data, but sitting at a computer until your butt goes to sleep is not pleasant. I understand now why some researchers are reluctant to undertake this type of research. I spent more time gathering data than for any other type of research class I had taken. When the research for the semester was completed, I had over 300 pages of field notes.

We frequently commiserated with each other about the workload, and we questioned whether all this detail and introspection was really necessary. None of our other courses seemed to have this much work; in fact, advanced statistical classes that required the mastery of statistical software packages were starting to look infinitely preferable in comparison. But despite the feeling that we were participating in qualitative researcher boot camp, we did feel a sense of pride and accomplishment when we looked 
at the mounds of data we had collected by getting out in the field and getting our hands dirty.

I did feel that I was doing "real sociology". ... I felt like I was really doing something - engaging in the contact and interaction that separated the qualitative sociologist from other sociologists. Turning in field notes and notes on notes each week, I anticipated the point when we would arrive as qualitative sociologists, that pinnacle toward the end when we would discuss the volume of our work - hundreds of pages of field notes.

As Kleinman and Copp (1993:19-21) point out, accumulating a thick data set may soothe fieldworkers' anxieties about their own credibility and the legitimacy of qualitative research. Given our status as neophytes, we were particularly vulnerable to these fears.

\section{Forming Relationships, Feeling Attachment}

As a green field researcher who had for the most part only crunched numbers for much of my academic career, the degree of personal investment and intimacy demanded by qualitative research proved wholly surprising. It's easy to ignore yourself when working with unresponsive numbers, but when you work with actual human subjects who react to you, to your actions, to your presence, it proves harder to ignore yourself. At least, that was true for me.

As the semester progressed, we became enmeshed in our subjects' lives and struggled with what it meant to be observers who were deeply involved. As the boxing researcher put it,

I would mentally prepare myself for the gym: "OK, let's not worry how I do tonight. I am a researcher just gathering data," I would say to myself. This would inevitably work for the first part of the gym workout. By the time I left each night, however, I was measuring myself not as a researcher, but as another boxer in the gym. In essence, I was every bit the boxer to the point that I would often even forget I was a researcher. While this is probably not a particularly good thing for a field researcher, I couldn't help it. For one, I couldn't really think 
about my research when I had a guy in front of me trying to pound my face in. Also, I had to worry about my progression as a boxer from the eyes of my fellow boxers; it became part of my ego. I wish I could have simply gone into my setting and not cared, but I did care. I wanted to excel in the gym, just as I had in my younger days in other sporting activities. Thus, I was having to deal with some emotional baggage as part of my research.

We increasingly worried that the relationships we were developing with our field sites and subjects would interfere with our ability to conduct ourselves as "good" researchers. This was no doubt due to the increasing emotional attachment to our field sites that was fostered by the closeness and intimacy of doing qualitative research and exacerbated by the emotional baggage we carried with us from our pasts. This worry may have in part been a carryover from lessons of detachment we had learned in our other methods courses (cf. Kleinman and Copp 1993:2 on positivism and the ideology of professionalism in science). It became clear to us that quantitative methods insulate researchers from subjects, not simply for objectivity's sake, but also for the researcher's sake. Rather than tempting a researcher to get "too attached," quantitative research offers a safe distance from potentially challenging or threatening subjects and issues. ${ }^{4}$

While it may seem like we should have known that interacting with people for months would foster attachment, the extent and intensity to which it did was surprising. We had read in the anthropological literature about the danger of "going native," but this seemed relevant only in "exotic" field sites and not something we would likely have to guard against. Still, our sites became captivating, even enthralling, for some of us. As the teen researcher described,

I found myself wanting to abandon school, secure a shit job, move into a small rundown apartment, get a tattoo and some nipple rings, and buy a whole new wardrobe heavy on black and leather. Truth be told, I actually went out and bought some combat boots. 
For others, attachment to a site led to more than just introspection. As the boxing researcher discovered, his emotional attachment to his site led him to defend the barbarism inherent in boxing whenever outsiders remarked upon it.

I became defensive when I had colleagues disparage boxing for being violent and barbaric: I would tell them, "Hey, in reality, there is a lot of strategy and technical know-how in boxing. It is not what it seems." Although this was partly correct, in that boxing was indeed technical and involved much strategy, I was quickly forgetting the essence of boxing, the brutal nature of the sport, the violence.

Moreover, he found himself developing personal relationships with his subjects and experiencing conflicting loyalties.

Working out with these people [boxers], I felt a bond - sort of like going to "war" together at least once a week. When we left at night, I felt these were my brothers and sisters. When trying to do analyses of my site, I feared writing about certain episodes that would make some of these people look bad, or even might make me look bad. For instance, one of my sparring partners went toe-to-toe with our female trainer and couldn't control his anger. He started unloading on her. In the gym this type of behavior is frowned upon, but it is not way out of line-sometimes emotions get the best of people, especially when gloves are flying. However, as a sociologist and as an observer I was both appalled and concerned for the safety of the woman. During my analyses I wondered how I would write this up, and wondered what the guy, my gym partner, would think if he read my study. This made me feel strange, like I was betraying a friend.

Similarly, the teen center researcher felt a distinct responsibility not only to accurately represent the lives of the teenage participants to outsiders, but also to defend his subjects, many of whom would be judged by outsiders as miscreants and delinquents.

I feel charged with the responsibility of determining exactly how the teens interpret and interact with their environment and of 
communicating that as fully and as precisely as possible. ... I want others to understand the problems that motivate their coping strategies - those that may seem curious or bizarre or even condemnable from afar.

The Girl Scout researcher also felt the desire to learn more about the lives of her subjects, not only to increase the richness of ethnographic data obtained, but also to satisfy a voyeuristic personal curiosity.

One of the mothers invited me to her home to interview her. Afterwards, she gave me a tour of her house and invited me up to her daughter's room, where she, her three kids, and I spent about a half an hour talking, looking at scrapbooks, and playing with the family's two pet hamsters. Even though I had somewhere to be that afternoon, I felt like it was more important for me to stay and hang out with them. Part of my motivation was that it would help me build trust with them and get better data as they opened up more to me. But then there was more than that. ... I also truly wanted to see what their lives were like, to learn as much as I could about these little girls and their families as people.

As we found ourselves playing the dual roles of participant and observer, we felt ourselves increasingly drawn in and conflicted. The closeness and intimacy of qualitative research magnified the similarities between us and our subjects, a form of attachment that seemed valuable for understanding what was happening in our sites. Yet, this attachment — which we faced alongside the typical pressure to prove ourselves as graduate student researchers - created psychological tension and feelings of vulnerability for which we were unprepared (cf. Behar 1996). Yet, not all of us felt this way. The law enforcement researcher experienced little of the emotional attachment described by the others. From her perspective she had successfully kept her distance in the name of research and remained "objective." However, by the end of her tenure at the police station, she too underwent a period of self-questioning regarding her distance in the field. Was it possible to be too detached? All of us thus had to confront unfamiliar questions: How 
close is too close? What constitutes excessive contact with our subjects? What if we don't get involved enough? Where is the middle ground between attachment and detachment? Even more problematic was the question of how much attachment we should divulge. Should we admit to feeling "over-attached"? Because of the nature of qualitative research, it is expected that fieldworkers will have powerful feelings toward their research participants (Kleinman and Copp 1993). But what if those strong feelings are sexual? When the teen center researcher was confronted with his own attraction to a research subject, he became traumatized by thinking about the ethical quandary he, as well as his subject, might be facing.

Easily, the factor most responsible for my emotional attachment and subsequent difficulties involved my attraction to Cynthia, one of the teen center workers, who possibly, and if so, inexplicably, showed some interest in me, which made everything so much worse... Again, I had not anticipated that there would be any risk whatsoever of that happening to me. ... I worried frequently that my actions may have been deceitful and manipulative, and it seems clear that on several occasions I engaged in such behavior in hopes of kindling a more romantic relationship with her. I took advantage of my position as researcher to conduct the study in such a way that increased my exposure to her, and I asked her interview questions that may have had more personal significance for me than for my research interests.... 5

As the rest of us learned about the teen center researcher's situation, it became clear why qualitative researchers may be afraid to admit the troublesome aspects of interactions in the field, especially sexual ones (Goode 1996; Warren 1988:31): divulging these feelings might raise questions about a researcher's competence, objectivity, and ethics (Van Maanen et al. 1993:vii). In our situation, each of us broached our problems and difficulties in the field within the security of our class discussions. Yet, as the teen researcher's essay on the emotions he faced during this experience reveals, our anxieties about such problems were far deeper than we ever let on-especially if they threatened to cast us as 
unprofessional in the eyes of other students or our professor (cf. Kleinman and Copp 1993:3-18).

These emotional difficulties became more than mere personal dilemmas. For example, the teen center researcher's attraction to the center staff member spilled over into his interactions with other subjects, leading him to question the extent to which his presence in the setting was affecting the teens emotionally (cf. Goode 1996). Despite his recognition of the predicament he was in, however, he still felt a powerful urge to rationalize and justify his actions.

I became quite critical of my actions in regard to Cynthia and actually warned her at one point that I may be abusing my role in order to be around her, so that she could guard against it. Despite trying to avoid possibly reproachful actions, at the time I was able to justify all of them as falling perfectly within the interests of my project, and, honestly, the rationalizations I used to justify those actions still seem persuasive to me.

At one point, the teen center researcher's actions even set the stage for him to be physically threatened by an adolescent male regular who disapproved of the relationship between the researcher and this teen center staff worker. Instead of defending himself against the actions, the researcher blamed himself for provoking the incident.

Adam's [a male teen center regular] threats came a couple of weeks after Cynthia had asked me out to dinner and a movie. [One night], he entered, totally drunk, threatening me with, "I'll kick your fuckin ass, if you fuck with Cynthia," as he smothered her with his body and fondling hands. ... According to the rules [against violence at the teen center], Adam would have to be banned for some amount of time for this outburst, and Cynthia feared this would ruin the close relationship she had cultivated with him and with many of the other teens. This ban also stood to jeopardize what little acceptance I had at the center. Perceiving this as an inevitable outcome, I actually suggested that the incident be blamed on me so that Adam could avoid being banned from a place where, if anything, he needed to spend more time. But everyone rejected the idea as ridiculous, since the incident had "absolutely nothing" to do with me.... 
As is apparent, the teen center researcher's emotional involvement extended far beyond the individual level, to the point that he became distressed about the possibility that he was harming his subjects and compromising his study. Again, this issue raises hard questions for the novice fieldworker about the line between attachment and inappropriateness. Must we withdraw from the field if a line is crossed? One thing we learned is that where such a line lies is not derivable from any textbook formula.

After three months of field research, the semester was over. Strangely, we didn't experience the elation we had expected to feel once our workload was lightened; in fact, we seemed to have problems getting out of our sites. The boxing researcher, for one, chose to stick with his site, using the guise of research to continue enjoying the adrenaline-filled workouts. Similarly, the teen center researcher, despite all the personal difficulties he experienced in his site, decided that he didn't want his stint to end and tried to make plans to stay connected to the people he had grown close to.

I told the teen center director that this would be my final observation and asked if she would handle the arrangements, if I provided the funding, for a pizza party as a thank you for allowing me access to the site. She happily agreed to organize the event but was confused by my unwillingness to attend. It seemed silly to me as well, but the truth was that exiting the site bothered me so much that I feared being overwhelmed emotionally by regret. Over the last several weeks the teen center had become a place for me to hang out on the weekend, and I had come to value that. Despite thinking that an abrupt severing of ties to the teen center would prove easier, when she invited me to stop by anytime, since they "always needed volunteers," I eagerly expressed my interest, asking her to call me ... I had actually hoped she would make such a suggestion.

The Girl Scout researcher, who discontinued her visits to the meetings at the end of the semester, had a hard time saying goodbye as well.

On my last day of observation ... I knew I probably would never see the girls again, and I was left wondering what would happen 
to each of them. Would they stay in Girl Scouts? What would they be like as teenagers? Where would they go to college? What would they end up doing with their lives? I have to say that when I ended my fieldwork, I felt a sense of withdrawal I hadn't at all been prepared for.

It was hard to leave because our research had connected us to people rather than to numbers and computers. After an intense semester of more work than we had bargained for, we were unprepared to let go.

\section{Analyzing Our Emotions}

Interestingly, I was totally myself at the site. Yet, I was also aware that I was the researcher. Therefore, I was wearing two hats. Each interaction, moment, experience, I was trying to analyze the situation in context of what was going on, which included my own thoughts and emotions.

My site forced me back into the reality from which I spent my life fleeing. It forced me to document this transition which I, at twenty-eight, had still not begun to negotiate. The teens I was studying knew in many practical ways more about the social world than I, someone about to attain a doctorate in sociology, and this new research method prevented me from denying it.

For all of us, fieldwork provoked considerable self-examination and personal reflection. In short, we first had to recognize, and then confront, the fact that our feelings and emotions, our actions, how we represented ourselves, our own backgrounds and personalities - everything - were all part of our study. The boxing researcher, in particular, found that he was unearthing more than simply his own feelings while spending time in the gym.

I quickly found that I enjoyed the pounding of boxing. I wondered why this was, but I also began feeling emotionally conflicted. Here I was a sociologist who abhorred violence, and not only was I participating in this barbaric sport, but I reveled in all its glory. ... I realized that my site [the boxing gym] and field research had slowly uncovered a semblance of my former hyper- 
masculinity, which had been in hibernation for almost a decade. This macho-ness was most evident in the night I proudly showed off my bloody mouthpiece to my wife while she looked at me with disgust. I loved it.

As emotional attachment led the boxing researcher to come to identify with participants, he realized to his distress that he was starting to "act masculine" in the same ways that he saw his subjects behaving

I remember it vividly-I was walking down the street, the day after a good workout at the gym, and I found myself "sizing up" other men on the street: looking to see how big they were, wondering if they were quick or not - thinking whether I could kick their asses. Although this wasn't the only time in my life I had those types of feelings, they had fortunately been in hiding since being an athlete in my undergraduate days. It seemed that the intense boxing training had uncovered these masculinity issues.

As the above data suggests, by confronting the emotions he felt during and after time spent boxing, the boxing researcher came to realize that his research participants might be feeling similar emotions. Previously, he had taken boxers' accounts of why they had gotten into the sport simply at face value-despite having been warned by our professor against doing so. ${ }^{6}$ For example, he accepted the stock answers that boxers gave, such as, "I wanted a good workout," "I wanted to learn self-defense," and "It's a place to work off frustration." No one said, "I wanted to feel manlier." Only by seeing that masculinity issues were clearly tied to his boxing experience was the boxing researcher able to realize that these same issues, whether consciously or subconsciously, could be part of the lens through which the research participants might view the sport of boxing as well. As such, the emotions that emerged on the part of the boxing researcher were used as analytical guides in doing his field work (Sprague 2005).

Recognizing his own masculinity issues, however, did not solve the boxing researcher's problems. In fact, it exacerbated them, as he became more and more aware of the fact that he was involved 
in a field site that centered on violence. In one instance, watching a sparring match between a male boxer and a female boxer at the gym prompted an emotional response on the part of the boxing researcher.

I was mad as hell that this guy would unload on somebody, especially a woman. What kind of guy hits women - even if it is in a gym? Then I stepped back and asked myself how I would have felt if he was hitting another man instead of a woman. Then I felt that maybe I was sexist for thinking that a woman should be treated differently at the gym. A host of issues along these lines thus ensued. How was I supposed to deal with anger that may be informed by my own masculinity?

By scrutinizing his own emotions and experiences through a sociological lens, the boxing researcher forced himself to rethink his perceptions of the boxing gym as a field site. Do women boxers break down the walls of essentialized gender ideologies when they participate in what is considered by some to be a "masculine" sport (Theberge 1997)? Even more striking to the researcher was the realization that his emotions pointed to a set of troubling beliefs about gender difference, beliefs that had been unconsciously affecting his analyses of the field site.

Similarly, personal reflection prompted the Girl Scout researcher to realize that her own experiences as a middle-class white woman were intimately tied to her perceptions of what was going on in her field site. Although she recognized that the processes of socialization in this middle-class, predominantly white Girl Scout troop helped perpetuate class, race, and gender inequality for its participants, her analysis did not fully mature until she came to realize that she had also participated in the same processes of social stratification that she saw taking place among this group of young girls.

It dawned on me: I myself had been socialized to behave like a proper middle-class white woman in the very same ways that I was observing these girls being socialized. I literally pondered this fact for days, and it haunted me because it pointed out all the gender and class ideologies that I myself reproduced on a daily basis. The process of analyzing what I saw in the field had 
made me take off my rose colored glasses and see myself as "data" too. I was no better than my informants, which meant that my study of the girls was equally a study of myself.

Prior to recognizing the fact that the researcher herself was a cog in the wheel of generic processes of inequality, just as the actors in this field site were, her analysis of the field site lacked a crucial analytical edge. Simply seeing race, class, and gender socialization at work was not enough to spark the critical consciousness of the Girl Scout researcher. Only when she recognized that socialization permeates the experiences and standpoints of all social actors, including herself, who grow up in a society stratified along these lines was she able to interpret how her particular field site carried greater sociological relevance.

A final piece of seemingly contradictory evidence also illustrates the relevance of emotionally charged analyses to sociological field research. In contrast to the experiences of the boxing researcher, the teen center researcher, and the Girl Scout researcher, all of whom were steeped in their field sites, the law enforcement observer never became attached to her subjects. At the end of the semester, as the rest of us discussed our attachment to our sites, the criminologist admitted that she couldn't quite understand what we were talking about. Only after her period of observation was over, when she compared her experiences to ours, did she confront her own lack of attachment to her field site - and make major inroads toward her analysis.

At first I wondered why my colleagues in class would talk about emotions so much. In my case [at the police station] I simply observed what I saw, had some conversations with the social actors in my site, did my interviews and went about the business of field research. Yet, when I began to think more about emotions [because of class discussions] I was able to turn the corner on my analysis. I realized that in some ways the station attempted to be sterile and emotionally detached. In this way they were able to keep me, the outsider, at bay. But it was more than that. Even between each other, there was almost an emotionless quality in their interactions. Humor and good-natured ribbing seemed to be a management strategy to quell emotions 
that might be somehow brought up on the job. This pattern became the crux of my analysis, and I'm not certain I would have been able to examine it sociologically if it hadn't been for the frank discussions we had in class regarding emotions in fieldwork. It's kind of funny how it all worked out.

Thus, whether emotions were at the heart of all of our stories from the beginning, or whether they entered the process almost as an afterthought, our analyses became stronger sociologically through our attempts to understand their role in our field research experiences.

Because we were able to interpret the broader significance of our role as researchers, we were also able to turn a critical eye on the field sites each of us had selected for our projects. As we reflected on our experiences in the field and our emotional attachment to these sites, we realized that they were meaningful to us as individuals in ways that exceeded simple research interests: our sites had personal connections, not to our present lives, but to earlier life situations that continued to influence us. The student who felt he had failed to successfully negotiate the transition from adolescence to adulthood elected to study a teen center; the researcher who had undergone intense class and gender socialization in her youth chose to study Girl Scout troop meetings that were attended primarily by white, middle-class girls; the professional who was interested in criminology elected to study fellow professionals in law enforcement; and the former athlete, who had not realized the athletic acumen he had cherished in his youth was still so deeply important to him, decided to conduct his field research at a boxing gym.

The fact that these sites appealed to our individual identities also made them appealing for practical reasons. None of us, especially since we were all first-time field researchers, wanted to choose a site or study a group that seemed too difficult or threatening; we wanted somewhere we could fit in easily. Although we were told to study a site that was not familiar to us from our dayto-day lives, we were not barred from choosing sites that felt comfortable to us. It is understandable that we were uninterested in straying far from our comfort zones. Perhaps we were afraid to 
venture too far into the unknown, or perhaps feeling pressure to find a site and gain access quickly led us to choose sites that spoke to us in some way, whether by being familiar or at least not entirely foreign to us (cf. Kleinman and Copp 1993:4, 8-9). Only at the end of our projects did we see the implications of these choices for our analyses.

Looking back on the process of field research, our emotions had been an obstacle for us until we confronted them directly in the context of analyzing the emergent social processes in our field sites. Through self-examination, we were able to sharpen our critical thinking skills and learned how to conduct a more sociologically mindful analysis. As the police station researcher put it,

Spending time in the field taught me the value of patience and time in uncovering, layer by layer, a site or a group. In this way, field research is similar to putting a jigsaw puzzle together. As the pieces fell into place, the picture began to take shape. But only when the last piece was in place did the complete picture come into view.

\section{Recommendations for Students and Teachers}

In presenting personal accounts of the fieldwork experiences by four graduate student neophytes, we recognize that our experiences are not necessarily generalizable to all new field researchers. We recognize that when giving advice to a beginner, he or she may not know the meaning of that advice, or how to act on it, until in the thick of a similar experience. Even then, the advice may go unheeded. Some skeptics might also argue that only when one undertakes a second project does advice make a difference. But regardless of when and to what extent our perspective is adopted, we believe our case study can benefit new fieldworkers, particularly graduate students, who might otherwise remain unaware of, or even be tempted to discount, the importance of their personal emotions as data and as a source of analytic insight. We thus draw on these experiences to make recommendations to those who teach graduate-level qualitative methods courses. 
For Students

1. Monitor your emotions and continually evaluate what they might mean to your study. Don't assume that emotions only crop up in in-depth or large-scale projects. As new researchers, we were most surprised that our emotions were so easily exposed in conducting field research over a relatively short period of time. Even more surprising, our emotional awareness assisted our analyses to varying degrees and was integral to analyses of our field sites. Although grappling with the emergence of emotions is challenging, we feel that being mindful of how and why emotions surfaced and what they mean is integral to one's research, even as graduate students. If ideas about how emotions are relevant to your project are not immediately obvious, start slow. For example, even identifying a few key emotional issues relevant to your project may assist you in formulating research questions or interview questions if and when you conduct interviews with subjects from the site.

2. alk to others-sociologists and/or non-sociologists, students and professors-about what is happening at your site (while maintaining confidentiality). Inside the qualitative classroom, it is important for the class as a whole to listen to your story and those of the other students about what is going on in your field sites. In our class, during the latter part of the semester, we all took a turn in the "hot-seat"-getting interrogated, sometimes grilled, by our colleagues and professor who had a litany of questions about our research. This process forced us to articulate what we thought was going on sociologically in our field sites and gave others the opportunity to criticize and shape our insights. This tactic can spark reflection about connections that might otherwise remain hidden. Talk to others outside the classroom as well. You may want to find a "qualitative buddy" who can sit down with you and ask about what is happening at your field site, from what they find interesting at your site to who are the most important people you have met so far and why. Some of our own most crucial introspective moments came from talking to a friend or col- 
league who happened to ask just the right question to get us on track. It is the amalgamation of these "a-ha" moments, whether they occur in class or with a colleague elsewhere, that often make it possible to bring a story together in a convincing and accurate way.

3. Think about where you fit into the sociological story. It is important for you to see your role as an actor on your own field site's "stage" (Boucher 2004). This mode of analysis is similar to emotional introspection, but it goes beyond simply taking inventory of one's emotions to think about how others perceive you and why. For instance, our police station researcher - a black woman - was never going to be "one of the (mostly white) guys" at the precinct, and this insight was crucial to helping her interpret the analytical story. Why wouldn't the officers accept an outsider? What would the implications have been, if they had accepted her as an insider? Your answers to questions like these-about your role as a researcher, your self-presentation to others at your field site, and your connections to them - may illuminate what might be happening in your field site and may spark analysis that could otherwise have gone unrecognized.

4. Keep a research journal. In addition to writing field notes and notes on notes, we advise going a step or two further and undertaking the much more introspective task of keeping a personal journal to track your emotions about your field site and your own role in it (see also Bean 1989; Reinertsen and Wells 1993). The journal would also be the impetus for a freewrite-type analysis if you think something is happening sociologically at your site but are not yet at the point of writing a formal analysis. This journal can be a stream of consciousness "spew" for you to write out your ideas in a format that allows you to break free from controlled writing. It can help you think more closely about your emotions and consider yourself and where you fit in the story. It can also serve as a place where you can try grouping together some of the sociological themes that you see happening at your site and then simply writing whatever comes to mind. The themes and patterns that 
emerge will certainly assist you when you begin the more focused and formal writing that is necessary to turn data and notes into an academic paper.

\section{For Instructors}

1. Employ the "head first" method in teaching qualitative courses. The first of our three recommendations for those who teach qualitative courses at the graduate level is a simple suggestion, but one we believe is especially vital. We recommend that instructors allow students to study a site for the entire semester and to dive in "head first" from beginning to end-thereby not only encouraging students to conduct their own field research but affording them the independence to learn by doing, rather than simply reading about qualitative work (cf. Astin 1993; Keen 1996). Many different hands-on techniques for teaching students about qualitative research have been employed; for example, some instructors require students to complete a few "mini" field studies, where they might spend a day or two at a couple different sites throughout the semester. Although these techniques give students a broad sense of qualitative research, we feel that it is more useful to experience the entire process, from beginning to end, finally writing a paper that is akin to an extended analytic memo (Lofland and Lofland 1984). By situating ourselves in one site for 15 weeks, rather than a few hours or weeks, we learned much more than how to conduct observations and write field notes, and we had the time both to make mistakes and to achieve successes. These experiences became the most valuable to us when it was time to analyze what was going on sociologically in our field sites. We felt certain that, despite the challenges that self-initiated and self-directed fieldwork entails, we preferred being allowed to become intimately familiar with the field site throughout the semester, rather than completing shorter research stints or conducting research with a more distanced hand.

2. Facilitate open discussion in the classroom. In conducting field research for the first time, as we have noted, there are 
many potential pitfalls, and a safety net is thus necessary. This safety net can be the classroom, a forum for discussing the challenges of fieldwork in general as well as students' specific successes and failures. These discussions were critical to our learning process, and we suggest that the classroom experience be structured to maximize the likelihood that frank, critical dialogue can take place. These discussions can be in groups or with the entire class, and students can talk about not only assigned readings, but also their own ongoing field experiences. ${ }^{7}$ Like any class, when a "safe place" is cultivated, it allows the free flowing and open discussions necessary to talk about even the most controversial, embarrassing, and sensitive issues, many of which come up in conducting qualitative research-especially when novice researchers are involved. Students need the opportunity to talk openly about what is happening at their sites, since dialogue often fosters critical thought and analysis. We also suggest that part of maintaining a supportive atmosphere in which students are comfortable sharing their experiences should involve reading others' accounts of field research, both by neophytes as well as seasoned researchers. For example, accounts like ours could be used in a qualitative research class to accompany readings such as Kleinman, Copp, and Henderson (1997) and Kleinman and Copp (1993). Having students read these articles not only at the beginning and the end of the course but throughout the semester should keep emotions salient to students and the instructor while keeping the classroom environment amenable to open discussions about the challenges of new student field research.

3. Have students write specifically about emotions. In addition to practical field notes and notes on notes (in which including feelings should be encouraged, Kleinman and Copp 1993:5760), we recommend that instructors engage students as often as possible in writing about their emotions. What emotions in general does fieldwork raise for them? What about specific events or situations related to their field sites? Revisiting these questions throughout the semester, at different stages in the research process - whether in the form of in-class freewrites, 
take home essays, journal assignments, or even exam questions - will uncover emotional connections that may otherwise go unnoticed. Such reflective techniques may be more profound for those doing participant observation, but we believe even students who are engaged in simply observing a site would sharpen their sociological understandings by attempting to understand the relationship between emotions, the researcher, the field site, and subjects in the field.

At the same time, the process of actually coming to (written) terms with the emotional issues surrounding field sites may be painstaking and slow for new field researchers. For us, even though emotional issues underlay our fieldwork experiences from start to finish, and despite the fact that our professor had been trying to get us to recognize this fact, our own unresolved personal issues kept us from hearing what he was saying. While he might have been able to see what was going on for each of us in the field, he probably could not have pushed us to see an analysis early in our fieldwork process, because we simply were not ready. When that readiness is achieved, however, it can open the door to new insight and clarity and facilitate intellectual growth. The teen center researcher made this final point in his introspective reflection:

Overall, I know I have become a better sociologist. I now "observe" the places and things around me with more of a sociological eye. Interestingly, I thought I did this before, but now I realized how well being the field researcher amplifies normal, everyday observations.

\section{Conclusions}

In our experience as novice field researchers, we encountered three major, unanticipated challenges. First, the process of conducting field research was time consuming and daunting in scopeeven compared to advanced statistical or other quantitative sociology courses. Second, it required us to learn to be mindful of our own emotions and monitor the effect of our personal involvement on our research in the form of our attachments to our subjects and 
the research choices we made. Third, the emotional issues we encountered while in the field - though they were a stumbling block at first because we were unable to interpret what they meant or how they were relevant to our studies - ultimately were catalysts for us to achieve analytical breakthroughs in which we developed keener insight into the social processes in our sites.

From our collective fieldwork experiences, in which we were "vulnerable humans who suffered, had doubts, and made mistakes" (Kleinman and Copp 1993:18), we emerged with no stronger impression than that qualitative research demands fieldworkers to become close to those they study. None of us had realized as novice fieldworkers that the detachment we had become accustomed to from our past experience with quantitative approaches could not be so easily replicated in this situation. Nor did we anticipate that instead, we would struggle with feelings of insecurity, over-rapport, sexual attraction, embarrassment, discouragement, and frustration. As graduate students new to the field, we had few of the coping resources that experienced researchers have developed. Except for the police station researcher, our inexperience with the emotional demands of qualitative research left us particularly susceptible to feelings of over-attachment. However, the apparent paradox is that our closeness, though it came at considerable emotional expense at the time, created and fostered the conditions for us to develop sociological insights as part of a rich research experience that we might not otherwise have gained. In addition, we learned that without self-awareness, fieldworkers will certainly have difficulty developing insight into others' lives; and at the same time, being mindful of others' emotions and what they signify can provide a window into the nuances of one's own self. As Kleinman and Copp (1993:32-34) reiterate, self-estrangement and distancing techniques that allow us to ignore our feelings only hinder our awareness and keep us from being analytical. As we learned first hand, one's sociological imagination is inseparable from the ability to introspect.

Although the emotional issues raised in this paper may not be germane to all field research interactions, we feel that they should be integral to discussions about how to conduct qualitative research, 
because they highlight the challenges that qualitative sociologists, particularly novice field researchers, are likely to face when venturing beyond the walls of academe. Sociologists must be prepared to continue to investigate how emotions are managed by fieldworkers, not only with regard to how they personally process the experience of field research, but with implications for how sociologists regard "subjectivity" in analyzing qualitative data and how we might continue to confront potentially gray areas related to ethical conduct in the field.

\section{Notes}

The authors would like to thank Michael Schwalbe for his comments and suggestions on drafts of this article. We are also grateful to Zachary Brewster and Sherryl Kleinman, as well as the anonymous reviewers of STAR, for their encouraging words, constructive criticisms, and helpful comments.

${ }^{1}$ We received permission from our instructor to write "our side" of the qualitative research story. He not only approved but also assisted us in reading drafts of the paper and providing useful feedback.

${ }^{2} \mathrm{He}$ was never told by the principal that he couldn't observe; rather, the school kept delaying his access until it seemed apparent that they weren't going to let him.

${ }^{3}$ The instructor had already explained to the hockey researcher in confidence that, yes, the lie that was told was harmless in that it was inconsequential for people at the hockey rink. However, in terms of establishing trust in the field, he explained that it was much more than an inconsequential white lie. It had become a trust issue, and it was therefore fundamentally fatal to the study. The hockey researcher was instructed to find a new site to study.

${ }^{4}$ We understand the danger of dichotomizing quantitative and qualitative research methods and/or disregarding the fact that there is indeed considerable overlap between the two methods (Sprague 2005). At the same time, however, we are attempting to point out some of the ways in which aspects of field research are "qualitatively different" than aspects of quantitative methods (Kleinman, Copp, and Henderson 1997).

${ }^{5}$ All names are pseudonyms.

${ }^{6}$ Sprague (2005:58) is also critical of transferring power to research 
subjects ("handing over the microphone"), asserting that in this scenario the researcher may inadvertently privilege the dominant discourse over critical ones.

${ }^{7}$ Ideally, qualitative field research classes should be small enough for students and professor to be able to engage with each other, individually, in small groups, and as a class, both informally and more formally.

\section{References}

Agar, Michael. 1994. Language Shock: Understanding the Culture of Communication. New York: William Morrow.

Astin, Alexander W. 1993. What Matters in College. San Francisco, CA: Jossey Bass.

Bean, Terry W. 1989. "Using Dialogue Journals to Foster Reflective Practice with Preservice, Content-Area Teachers." Teacher Education Quarterly 16:33-40.

Behar, Ruth. 1996. The Vulnerable Observer: Anthropology that Breaks Your Heart. Boston: Beacon Press.

Boucher, Gerard W. 2004. "The Necessity of Including the Researcher in One's Research." General qualitative research, Research methods resources on the WWW. School of Library, Archival and Information Studies. http://www.slais.ubc.ca/resources/research_methods/ general.htm.

Ellis, Carolyn. 1991. "Sociological Introspection and Emotional Experience." Symbolic Interaction 14:23-50.

-1995. "Emotional and Ethical Quagmires in Returning to the Field." Journal of Contemporary Ethnography 24:68-98.

Goode, Erich. 1996. "The Ethics of Deception in Social Research: A Case Study." Qualitative Sociology 19:11-33.

Keen, Mike F. 1996. "Teaching Qualitative Methods: A Face-to-Face Encounter.” Teaching Sociology 24:166-76.

Kleinman, Sherryl. 1991. "Field-workers' Feelings: What We feel, Who We Are, How We Analyze." Pp. 184-95 in Experiencing Fieldwork: An Inside View of Qualitative Research, edited by W.B. Shaffir and R.A. Stebbins. Newbury Park, CA: Sage.

— Park, CA: Sage.

— Martha A. Copp, and Karla Henderson. 1997. "Qualitatively Different: Teaching Fieldwork to Graduate Students." Journal of Contemporary Ethnography 25:469-99. 
Labaree, Robert V. 2002. "The Risk of 'Going Observationalist': Negotiating the Hidden Dilemmas of Being an Insider Participant Observer." Qualitative Research 2:97-122.

Lofland, John, and Lyn Lofland. 1984. Analyzing Social Settings. Belmont, CA: Wadsworth.

McGrath, John E, Joanne Martin, and Richard A. Kulka. 1982. Judgment Calls in Research. Newbury Park, CA: Sage.

Monti, Daniel J. 1992. "On the Risks and Rewards of "Going Native."” Qualitative Sociology 5:325-332.

Reinertsen, Priscilla S., and M. Cyrene Wells. 1993. "Dialogue Journals and Critical Thinking." Teaching Sociology 21:182-86.

Sieber, Joan E. 1982. The Ethics of Social Research: Fieldwork, Regulation, and Publication. New York, NY: Spinger-Verlag.

Shaffir, William B., and Robert A. Stebbins. 1991. Experiencing Fieldwork: An Inside View of Qualitative Research. Newbury Park, CA: Sage.

Smith, Allen, and Sherryl Kleinman. 1989. "Managing Emotions in Medical School: Students' Contacts with the Living and the Dead." Social Psychology Quarterly 52:56-69.

Snow, David. 1980. "The Disengagement Process: A Neglected Problem in Participation Observation Research." Qualitative Sociology 3:100122.

Sprague, Joey. 2005. Feminist Methodologies for Critical Researchers. Walnut Creek, CA: Altamira Press.

Theberge, Nancy. 1997. “'It's Part of the Game': Physicality and the Production of Gender in Women's Hockey." Gender \& Society 11:69-87.

Van Maanen, John. 1988. Tales from the Field: On Writing Ethnography. Chicago: University of Chicago Press.

—, ed. 1995. Representation in Ethnography. Newbury Park, CA: Sage.

— , Phillip K. Manning, and M.L. Miller. Pp. vii-viii in "Editors' Introduction." In Emotions and Fieldwork, by S. Kleinman and M.A. Copp. Newbury Park, CA: Sage.

Warren, Carol. 1988. Gender Issues in Field Research. Newbury Park, CA: Sage.

Wax, Murray. 1979. "On the Presentation of Self in Fieldwork: The Dialectic of Mutual Deception and Disclosure." Humanity and Society 3:248-259. 